\section{Premenstrual symptoms and syndrome according to age at menarche in a 1982 birth cohort in southern Brazil}

\author{
Descrição de sintomas e síndrome pré-menstrual \\ conforme a idade da menarca em mulheres \\ nascidas em 1982, no Sul do Brasil
}

Celene Maria Longo da Silva 1

Denise Petrucci Gigante 1,2

Gicele Costa Minten 1

\footnotetext{
${ }^{1}$ Faculdade de Medicina, Universidade Federal de Pelotas, Pelotas, Brasil. 2 Faculdade de Nutrição, Universidade Federal de Pelotas, Pelotas, Brasil.

Correspondence

C. M. L. Silva

Departamento de Medicina Social, Faculdade de Medicina, Universidade Federal de Pelotas. Av. Duque de Caxias 250, 2o andar, Pelotas, RS 96030-000, Brasil. celene.longo@terra.com.br
}

\begin{abstract}
Premenstrual symptoms and syndrome were studied in young women who have been followed since birth. Data were collected on the intensity of four symptoms: irritability, anxiety or stress, depressed mood, and affective lability. Premenstrual syndrome was defined according to intensity of symptoms. Association between age at menarche and premenstrual symptoms and syndrome were investigated through Poisson regression. Adjusted analysis was conducted, controlling for possible confounding factors. The symptoms most frequently reported by the women from the 1982 Pelotas, Rio Grande do Sul, Brazil, birth cohort who were interviewed in 2004-2005 were: irritability (52.3\%) and anxiety (40.2\%). The prevalence rates for moderate and severe premenstrual syndrome were $13.4 \%$ and $5.8 \%$, respectively. Mean age at menarche was $12.4( \pm 1.5)$ years. Prevalence rates for symptoms and premenstrual syndrome were higher in women whose age at menarche was less than 11 years, but this difference was not statistically significant. Information on symptoms and premenstrual syndrome is scarce in other studies.
\end{abstract}

Premenstrual Syndrome; Menstrual Cycle; Menarche; Women

\section{Introduction}

Premenstrual syndrome (PMS) can be defined as a set of physical, emotional, and behavioral symptoms that appears in the premenstrual phase and presents rapid resolution when menstruation begins. The symptoms are cyclical and recurrent. Although in some women this premenstrual experience can be very intense 1,2 , not all women consider it a harmful obstacle to their daily routine.

Few population-based studies have quantified premenstrual symptoms. One of these studies, in a cohort of 21-35-year-old women in $\mathrm{Zu}$ rich, Switzerland, found prevalence rates for severe and moderate peri-menstrual symptoms of $8.1 \%$ and $13.6 \%$, respectively ${ }^{3}$. Another cohort of women 14 to 24 years of age in Munich, Germany, found relatively stable symptoms in four years of follow-up. While the initial prevalence rate was $5.8 \%$, cumulative incidence was $7.4 \%$ for severe symptoms, defining premenstrual dysphoric disorder (PMDD) as the most severe form of PMS 4. In the same study, the prevalence of subliminal PMDD, that is, women who report severe symptoms but do not meet the criteria for PMDD because they report absence of impairment in daily life, was $18.6 \%$. PMDD is classified as a mental disorder under the Diagnostics and Statistical Manual of Mental Disorders (DSM IV TR) 5, and its prevalence rates among women 15 to 49 years range from $3 \%$ to $8 \% 1$. 
In Pelotas, Rio Grande do Sul State, Brazil, a population-based study in 2003 in women 15 to 49 years of age found an inverse relationship between PMS prevalence and women's age. Prevalence of PMS among adolescents (15-19 years) was $30 \%$ higher than in older women (4049 years) 6 . In addition to age, other factors such as higher schooling, white skin color, and higher socioeconomic status were also associated with PMS. The majority of these women reported at least one of the following symptoms: irritability, abdominal discomfort, nervousness, health, and tender breasts during the premenstrual period.

Other studies have also found an association between PMS and younger age 6,7, higher socioeconomic status 6, smoking 4,7, alcohol abuse 7, mental stress 4,7 etc. However, no study was found in the literature on the effect of age at menarche on PMS.

Adolescence is the period of life between childhood and adulthood. Puberty is the first phase of adolescence in which the first signs of sexual maturation appear: the initial phenomenon is the development of breasts, or telarche, followed by the development of pubic hairs or pubarche, and culminating with the first menstrual period, or menarche. Menarche is an important biological and clinical marker for this sexual maturation, signaling the beginning of reproductive life 2 . It is believed that the way adolescent girls experience this phase of their development has an important impact on the quality of their adult lives ${ }^{8}$.

Western countries have witnessed a downward secular trend in age at menarche, as corroborated in a Brazilian study ${ }^{9}$, and this change has been interpreted as a consequence of environmental, socioeconomic, nutritional, and cultural factors. Thus, an association between obesity and younger age at menarche has also been observed more recently 10 , while there are reports of later menarche in athletes and girls living in rural areas 11. However, despite these concepts, there is no consensus on the definition of early or late menarche ${ }^{2}$.

The current study aims to investigate a potential association between age at menarche and the manifestation of premenstrual symptoms or PMS in young women, considering the possibility that socioeconomic, demographic, or behavioral factors may be impacting this association.

\section{Methods}

This study is part of a longitudinal cohort in which all births in the year 1982 in the maternity wards/hospitals of Pelotas were included in a perinatal study. In that first follow-up, questionnaires were applied by interviewers who screened the births daily and interviewed the mothers in the maternity hospitals. This was the beginning of the 1982 cohort study, and the next follow-up was done with a home visit, using the address provided on the perinatal questionnaire. For the cohort follow-up, interviewees were located through a citywide household census. In the initial interviews, during childhood, the mothers answered for the children, and in the follow-up visits during adolescence, questionnaires were applied to mothers and the girls themselves. In the last follow-up, at a mean age of 23 years (in the 2004-2005 visit), the questionnaire was only applied to the young women from the 1982 cohort. In this most recent visit, with all the young people from the cohort, in addition to the household census, a search was conducted for the addresses obtained through the previous follow-up visits or through secondary and technical school enrollment lists and university admissions exam lists from the previous five years at the city's five largest universities. Deaths in the cohort have been identified through the Mortality Information System (SIM) 12. The methods used in this cohort's follow-up have been published elsewhere 13,14

In the last follow-up with the entire cohort, the fieldwork was done from October 2004 to August 2005. In addition to the interviews conducted in Pelotas, individuals residing in other municipalities were invited to come to Pelotas for the interview and a research team visited the main cities in the region where there was an important number of young residents residing there, but who belonged to the Pelotas birth cohort. General information on some of the results obtained in previous follow-up visits, highlighting the importance of participating in the study, was publicized through a folder provided during the interview.

The interviewers were females with complete secondary schooling. A selection process was conducted and the interviewers received specific training that included information on application of the research instrument and procedures to be followed during the interview. Quality control was applied to $10 \%$ of the interviews, repeating some questions from the questionnaire.

The variables used in this analysis were obtained since the perinatal follow-up: mother's age at birth date of the interviewee, mother's schooling, both in complete years, family income expressed as times the prevailing minimum wage, smoking during the pregnancy in number of cigarettes per day, mother's skin color (white/non-white) as observed by the interview- 
er, birth weight in grams, gestational age in weeks since date of last menstrual period as reported by the interviewee, duration of breastfeeding in months, and age at menarche, in complete years, the latter obtained during the follow-up visits in childhood and adolescence. Early menarche in this study was defined as first menstruation at 10 years or younger and late menarche as 15 years or older. The current socioeconomic, demographic, and behavioral variables were: schooling in complete years of study, family income in reais, skin color reported by the interviewee, number of children reported by the interviewee, body mass index (BMI) calculated as weight in kilograms divided by height in meters squared on the interview date, smoking in three categories: non-smoker, current smoker, or former smoker, and the Self-Reported Questionnaire (SRQ-20) including 20 questions for screening minor mental disorders.

The outcomes in this analysis were obtained from information on the premenstrual variables, including four symptoms: irritability, stress or anxiety, episodes of weeping, and depression. Each of these symptoms was investigated at four levels of intensity (zero, low, moderate, and high). The report of intensity was considered as absence of symptoms (none), mild (a little), moderate (more or less), and severe (high). This information was used to construct a continuous score in which symptom intensity was transformed into a numerical value from 0 (none) to 3 (high). Interviewees who reported at least one symptom were asked whether it impaired their contact with others, also with four possibilities: none (0), a little (1), more or less (2), and high (3). The outcomes included each of the four symptoms analyzed as moderate and severe intensities. Another outcome, called moderate PMS, was constructed for those who presented at least eight points in symptoms and with impairment in personal relations, at the stronger intensities: more or less (2) or high (3), while severe PMS was characterized when interviewees reported severity (high $=3$ ) for the four symptoms and moderate to great difficulty in contact with other persons.

The analysis included women with regular menstrual periods in the previous three months and those who had used continuous hormonal contraception to avoid menstruating.

Calculation of statistical power for the sample size in a population where $7.5 \%$ of the women had menstruated for the first time between 7 and 10 years of age and with a $12.7 \%$ prevalence rate for moderate PMS in the group with mencarche in the adequate age range (11 -14 years) showed that the study would have the power to find a prevalence ratio greater than or equal to 1.76 , or a prevalence rate of $22.4 \%$ among the exposed.

Data analysis used Stata 9.2 (Stata Corp., College Station, USA), summarizing the mean values for symptoms, exposure and outcome prevalence rates, chi-squared test for associations, and stratified analysis of symptoms and forms of PMS with the categories for age at menarche, BMI, skin color, number of children, SRQ-20, family income, schooling, and smoking. The adjusted analysis to control for confounding considered variables whose crude association with the outcomes presented a $\mathrm{p}$ value $\leq 0.2$. The prevalence ratio was calculated using Poisson regression, with robust variance. The sample size was calculated using Epi Info (Centers for Disease Control and Prevention, Atlanta, USA).

The study protocol was submitted to and approved by the Research Ethics Committee at the Federal University in Pelotas. All the interviewees were informed of the study objectives and provided verbal and written consent.

\section{Results}

Of the 2,876 women from the 1982 live birth cohort, 2,082 were interviewed during the 20042005 visit (Table 1). Considering that 119 women (4.1\%) had already been identified as having died, $238(8.3 \%)$ were losses to follow-up or refusals, and $438(15.2 \%)$ were not located, the follow-up rate was $76.5 \%$.

Comparison of the characteristics of the women interviewed at 22-23 years and those of all the women in the cohort showed a similar distribution in relation to several variables collected in the first follow-up visits. Mortality was proportionally lower among daughters of women with white skin and those who were over 30 years of age, had 12 or more years of schooling, and came from higher-income families. Meanwhile, mortality was proportionally higher among young women with birth weight less than 2,500g, born at gestational age less than 37 weeks, and who were breastfed for less than a month (Table 1).

Table 1 also shows a higher proportion of losses and refusals among young women with higher socioeconomic status at birth, i.e., whose mothers had more schooling, white skin color, and family income greater than three times the prevailing minimum wage. Meanwhile, among those not located in the 2004-2005 follow-up, the most frequent characteristics were being daughters of teenage mothers and mothers with less schooling and with family incomes of less than one minimum wage in 1982. 
Characteristics of women in the 1982 birth cohort and proportion of women located in the 2004-2005 follow-up visit, Pelotas, Rio Grande do Sul State, Brazil, 1982-2005.

\begin{tabular}{|c|c|c|c|c|c|c|c|c|c|c|}
\hline \multirow[t]{3}{*}{ Characteristics * } & \multirow{2}{*}{\multicolumn{2}{|c|}{$\begin{array}{c}1982 \text { visit } \\
\text { (interviewees) }\end{array}$}} & \multicolumn{8}{|c|}{$2004-2005$ visit } \\
\hline & & & \multicolumn{2}{|c|}{ Interviewees } & \multicolumn{2}{|c|}{ Deaths } & \multicolumn{2}{|c|}{ Losses and refusals } & \multicolumn{2}{|c|}{ Not located } \\
\hline & $\mathrm{n}$ & $\%$ & $\mathrm{n}$ & $\%$ & $\mathrm{n}$ & $\%$ & $n$ & $\%$ & $\mathrm{n}$ & $\%$ \\
\hline \multicolumn{11}{|c|}{ Mother's age (years) } \\
\hline$<20$ & 442 & 15.4 & 307 & 14.8 & 19 & 16.0 & 29 & 12.2 & 87 & 20.0 \\
\hline $20-29$ & 1,646 & 57.3 & 1,178 & 56.6 & 74 & 62.2 & 136 & 57.4 & 259 & 59.1 \\
\hline$\geq 30$ & 787 & 27.4 & 597 & 28.7 & 26 & 21.9 & 72 & 30.4 & 92 & 21.0 \\
\hline \multicolumn{11}{|c|}{ Mother's schooling (years) } \\
\hline $0-4$ & 952 & 33.1 & 687 & 33.0 & 54 & 45.4 & 52 & 21.9 & 159 & 36.3 \\
\hline $5-8$ & 1,166 & 40.6 & 870 & 41.8 & 48 & 40.3 & 93 & 39.1 & 155 & 35.4 \\
\hline $9-11$ & 324 & 11.3 & 234 & 11.3 & 12 & 10.1 & 32 & 13.5 & 46 & 10.5 \\
\hline$\geq 12$ & 432 & 15.1 & 289 & 13.9 & 5 & 4.2 & 61 & 25.6 & 78 & 17.8 \\
\hline \multicolumn{11}{|c|}{ Family income (times minimum wage) } \\
\hline $0.0-1.0$ & 622 & 21.7 & 413 & 20.0 & 42 & 35.6 & 41 & 17.2 & 126 & 29.0 \\
\hline $1.01-3.0$ & 1,325 & 46.4 & 1,031 & 49.8 & 52 & 44.1 & 86 & 36.1 & 157 & 36.1 \\
\hline $3.01-6.0$ & 547 & 19.1 & 383 & 18.5 & 17 & 14.4 & 58 & 24.4 & 89 & 20.5 \\
\hline $6.01-10.0$ & 198 & 6.9 & 122 & 5.9 & 5 & 4.2 & 29 & 12.2 & 42 & 9.7 \\
\hline$\geq 10.01$ & 168 & 5.9 & 121 & 5.8 & 2 & 1.7 & 24 & 10.1 & 21 & 4.8 \\
\hline \multicolumn{11}{|c|}{ Smoking during pregnancy (cigarettes/day) } \\
\hline None & 1,864 & 64.8 & 1,343 & 64.5 & 76 & 63.9 & 168 & 70.6 & 277 & 63.5 \\
\hline $1-14$ & 787 & 27.4 & 580 & 27.9 & 33 & 27.7 & 49 & 20.6 & 125 & 28.5 \\
\hline$\geq 15$ & 225 & 7.8 & 159 & 7.6 & 10 & 8.4 & 21 & 8.8 & 35 & 8.0 \\
\hline \multicolumn{11}{|l|}{ Skin color } \\
\hline White & 2,371 & 82.5 & 1,715 & 82.4 & 81 & 68.1 & 210 & 88.6 & 366 & 83.6 \\
\hline Non-white & 504 & 17.5 & 367 & 17.6 & 38 & 31.9 & 27 & 11.4 & 72 & 16.4 \\
\hline \multicolumn{11}{|c|}{ Birth weight (grams) } \\
\hline $1,170-2,499$ & 289 & 10.1 & 164 & 7.9 & 58 & 49.6 & 29 & 12.2 & 39 & 8.9 \\
\hline $2,500-2,999$ & 768 & 26.7 & 570 & 27.4 & 31 & 26.5 & 55 & 23.1 & 112 & 25.6 \\
\hline $3,000-3,499$ & 1,089 & 37.9 & 785 & 37.7 & 19 & 16.2 & 107 & 45.0 & 178 & 40.6 \\
\hline $3,500-3,999$ & 611 & 21.3 & 486 & 23.4 & 7 & 6.0 & 37 & 15.6 & 81 & 18.5 \\
\hline $4,000-5,200$ & 116 & 4.0 & 76 & 3.7 & 2 & 1.7 & 10 & 4.2 & 28 & 6.4 \\
\hline \multicolumn{11}{|c|}{ Gestational age (weeks) } \\
\hline $26-35$ & 60 & 2.7 & 34 & 2.1 & 14 & 21.4 & 6 & 3.2 & 6 & 1.7 \\
\hline $36-37$ & 236 & 10.4 & 177 & 10.7 & 9 & 12.9 & 15 & 7.9 & 35 & 10.1 \\
\hline $38-39$ & 874 & 38.6 & 627 & 37.7 & 26 & 37.1 & 92 & 48.7 & 129 & 37.3 \\
\hline $40-41$ & 843 & 37.2 & 620 & 37.3 & 15 & 20.0 & 61 & 32.3 & 147 & 42.8 \\
\hline $42-44$ & 253 & 11.1 & 204 & 12.3 & 6 & 8.6 & 15 & 7.9 & 28 & 8.1 \\
\hline \multicolumn{11}{|c|}{ Breastfeeding (months) } \\
\hline$<1$ & 535 & 20.6 & 416 & 20.5 & 18 & 39.1 & 41 & 18.1 & 60 & 20.1 \\
\hline $1-2.9$ & 696 & 26.8 & 529 & 26.1 & 12 & 26.1 & 68 & 30.0 & 87 & 29.2 \\
\hline $3.0-5.9$ & 601 & 23.1 & 469 & 23.2 & 9 & 19.6 & 55 & 24.2 & 68 & 22.8 \\
\hline $6.0-8.9$ & 236 & 9.1 & 191 & 9.4 & 3 & 6.5 & 15 & 6.6 & 27 & 9.1 \\
\hline $9.0-11.9$ & 95 & 3.7 & 76 & 3.8 & 2 & 4.4 & 8 & 3.5 & 9 & 3.0 \\
\hline$\geq 12$ & 434 & 16.7 & 354 & 17.0 & 2 & 4.4 & 40 & 17.6 & 47 & 15.8 \\
\hline \multicolumn{11}{|c|}{ Interviewee's schooling in 2004-2005 (years) } \\
\hline $0-4$ & & & 141 & 6.8 & & & & & & \\
\hline $5-8$ & & & 490 & 23.5 & & & & & & \\
\hline $9-11$ & & & 1,060 & 50.9 & & & & & & \\
\hline$\geq 12$ & & & 393 & 18.9 & & & & & & \\
\hline
\end{tabular}

(continue) 


\begin{tabular}{|c|c|c|c|c|c|c|c|c|c|c|}
\hline \multirow[t]{3}{*}{ Characteristics * } & \multirow{2}{*}{\multicolumn{2}{|c|}{$\begin{array}{c}1982 \text { visit } \\
\text { (interviewees) }\end{array}$}} & \multicolumn{8}{|c|}{ 2004-2005 visit } \\
\hline & & & \multicolumn{2}{|c|}{ Interviewees } & \multicolumn{2}{|c|}{ Deaths } & \multicolumn{2}{|c|}{ Losses and refusals } & \multicolumn{2}{|c|}{ Not located } \\
\hline & $\mathrm{n}$ & $\%$ & $\mathrm{n}$ & $\%$ & $\mathrm{n}$ & $\%$ & $n$ & $\%$ & $\mathrm{n}$ & $\%$ \\
\hline \multicolumn{11}{|c|}{ SRQ-20 at $22-23$ years (points) } \\
\hline$<8$ & & & 1,394 & 67.2 & & & & & & \\
\hline$\geq 8$ & & & 681 & 32.8 & & & & & & \\
\hline \multicolumn{11}{|l|}{$\mathrm{BMI}$ at $22-23$ years } \\
\hline Underweight & & & 150 & 7.2 & & & & & & \\
\hline Normal weight & & & 1,370 & 65.8 & & & & & & \\
\hline Overweight & & & 371 & 17.8 & & & & & & \\
\hline Obese & & & 190 & 9.1 & & & & & & \\
\hline
\end{tabular}

SRQ-20: Self Reported Questionnaire; BMI: body mass index.

* Information lacking in some cases (n) for the following variables: mother's age (1), mother's schooling (2), family income (16), skin color (1), birth weight (3), gestational age (610), and duration of breastfeeding (279), so the sum of absolute numbers does not reach the total number of women studied.

At the visit in 2004-2005, approximately half of the women in the cohort (50.9\%) had 9 a 11 years of schooling and nearly a fifth (18.9\%) had at least 12 complete years of schooling. The screening instrument for minor mental disorders (SRQ-20) showed an altered result $(\geq 8)$ in approximately one-third of the interviewees. More than one-fourth (26.9\%) were above adequate weight (overweight or obese) at 22-23 years (Table 1).

Table 2 shows the characteristics related to menstruation in the 2,082 interviewees. Premenstrual symptoms were analyzed for 1,669 (80.1\%) women who menstruated regularly and 75 (3.6\%) who used a hormonal method to avoid menstruating. In relation to distribution of symptoms, irritability was the most frequent, and some twothirds of the women reported some difficulty in their family contact caused by these symptoms. Only 287 women (16.5\%) did not present any symptoms, and 111 (6.4\%) reported all the symptoms as intense, that is, with a score of 12 points. The mean total of intensities for the four symptoms was 4.6 points, with a standard deviation (SD) of 3.7.

Moderate PMS was present in 233 women $(13.4 \%)$, but when considering only severe symptoms, with moderate or intense difficulty in contact with others, the prevalence was $5.8 \%$, referred to as severe PMS (Table 2).

Of the interviewees who reported using pharmacological treatment for PMS (68 women), only eight used continuous oral contraceptives to avoid menstruating. In addition, 448 women (25.7\%) women reported having used hormonal contraceptives in the previous two weeks.

For all the women interviewed, age at menarche varied from 7 to 19 years, and only one woman had never menstruated. Mean age at menarche was 12.4 years (SD: \pm 1.5 ), and the median was 12 years. Only $15.5 \%$ menstruated for the first time outside the 11 to 14-year range (Figure 1).

When analyzing the frequency of symptoms according to age at menarche divided into three categories, higher prevalence rates are observed for the two intensities of all the symptoms in the extreme age brackets, although this difference is only statistically significant for symptoms of anxiety or stress in the intense form and for depression in the moderate form. Women with menarche from 11 to 14 years of age also presented lower prevalence rates for the two definitions of PMS (moderate and severe), but the differences also failed to reach statistical significance (Table 3 ).

Table 4 shows the gross and adjusted effects, as expressed by prevalence ratios, for age at menarche in relation to premenstrual symptoms and moderate and severe PMS. For each of the intensities of the four symptoms and for PMS assessed on the basis of these symptoms, the gross prevalence ratio ranged from $9 \%$ to $54 \%$ greater among women with menarche between 7 and 10 years of age. In those with menarche after 15 years of age, the gross effect ranged from $1 \%$ to $33 \%$. In the adjustment for possible confounding factors, i.e., those associated with age at menarche and each of the outcomes, the gross and adjusted values were quite similar for all the symptoms and for the two definitions of PMS (Table 4). Associations that were found in the crude analyses but which did not remain after adjustment were not included in the table; for example, SRQ-20 $\geq 8$ was significantly associated with all the premenstrual symptoms, without modifying the association between age at menarche and the PMS out- 
Table 2

Menstrual characteristics, premenstrual symptoms, and prevalence of premenstrual syndrome (PMS) in women from the 1982 birth cohort in Pelotas, Rio Grande do Sul State, Brazil, 2004-2005

\begin{tabular}{|c|c|c|}
\hline Variables (N) & $\mathbf{n}$ & $\%$ \\
\hline \multicolumn{3}{|c|}{ Regular menstruation in the last three months $(2,080)$} \\
\hline No & 236 & 11.4 \\
\hline Yes & 1,666 & 80.1 \\
\hline Currently pregnant & 103 & 4.9 \\
\hline Using continuous contraception & 75 & 3.6 \\
\hline \multicolumn{3}{|l|}{ Irritable $(1,740)$} \\
\hline No & 459 & 26.4 \\
\hline A little & 371 & 21.3 \\
\hline More or less & 341 & 19.6 \\
\hline Considerably & 569 & 32.7 \\
\hline \multicolumn{3}{|l|}{ Anxious or tense $(1,740)$} \\
\hline No & 634 & 36.4 \\
\hline A little & 406 & 23.3 \\
\hline More or less & 312 & 17.9 \\
\hline Considerably & 388 & 22.3 \\
\hline \multicolumn{3}{|l|}{ Prone to weeping $(1,740)$} \\
\hline No & 896 & 51.5 \\
\hline A little & 285 & 16.4 \\
\hline More or less & 235 & 13.5 \\
\hline Considerably & 324 & 18.6 \\
\hline \multicolumn{3}{|l|}{ Depressed $(1,740)$} \\
\hline No & 989 & 56.8 \\
\hline A little & 325 & 18.7 \\
\hline More or less & 197 & 11.3 \\
\hline Considerably & 229 & 13.2 \\
\hline \multicolumn{3}{|c|}{ Experiences difficulty in contact with other persons $(1,452)$} \\
\hline No & 479 & 33.0 \\
\hline A little & 506 & 34.9 \\
\hline More or less & 212 & 14.6 \\
\hline Considerable & 255 & 17.6 \\
\hline \multicolumn{3}{|l|}{ Self-reported PMS $(1,740)$} \\
\hline No & 658 & 37.8 \\
\hline Yes & 1,082 & 62.2 \\
\hline \multicolumn{3}{|l|}{ Moderate PMS $(1,739)$} \\
\hline No & 1,506 & 86.6 \\
\hline Yes & 233 & 13.4 \\
\hline \multicolumn{3}{|l|}{ Severe PMS $(1,739)$} \\
\hline No & 1,639 & 94.2 \\
\hline Yes & 100 & 5.8 \\
\hline \multicolumn{3}{|c|}{ Past or current treatment for PMS $(1,740)$} \\
\hline No & 1,672 & 96.1 \\
\hline Yes & 68 & 3.9 \\
\hline
\end{tabular}

comes. Importantly, when controlled, the effects of early or late age at menarche were lower than when not controlled, without reaching statistical significance for any of the outcomes.

\section{Discussion}

This study included the population of women from the 1982 Pelotas birth cohort, which has been followed for 23 years. The follow-up rate for the women who were interviewed in 20042005 can be considered adequate, in light of the fact that many of the young women in this age bracket may have left Pelotas in search of better schooling and work.

The mortality rate estimated by the Instituto Brasileiro de Geografia e Estatística [IBGE, Brazilian Institute of Geography and Statistics] for Brazil is 67 and 71 deaths per 100 thousand inhabitants, respectively, for individuals 22 and 23 years of age 15 . The mortality rate in this study was 70.6 per 100 thousand women, considering 119 known deaths in a population of 168,599 women in Pelotas 15. Thus, the results of the present study, showing that the survival rate in these women is higher among those with birth weight greater than $3,000 \mathrm{~g}$, gestational age 40 weeks or greater, breastfed for three months or more, and belonging to families with incomes greater than three times the minimum wage, are consistent with the data from IBGE 16 .

Although refusals were more common among women with higher socioeconomic status, those who were not located belonged mostly to lowerincome families. Thus, the distribution of economic level for the women interviewed here was similar to that observed in 1982, and this loss of some women at the extremes of family income could decrease the effect of the possible associations that were found.

Oral contraceptives have been prescribed to relieve premenstrual symptoms 17 , and in the present study some one-fourth of the women were using this method. If this treatment actually works, the results may be underestimated due to a reverse causality bias, i.e., the presence of premenstrual symptoms in the past may have led to the use of hormonal contraception and consequently the relief of symptoms. Considering as well that some women use oral contraceptives continuously to avoid premenstrual symptoms, these women were maintained in the analysis, even though this could have led to a decrease in the effect of some variables on the outcomes.

The prevalence rates for moderate and severe PMS were consistent with those found in other studies $3,4,6,7$. Irritability was also the most common symptom reported in some studies $6,18,19$, while others pointed to stress 20 or depression 1,21 as the most frequent symptoms. Note that the comparison between studies may not be adequate, considering that different instruments are being used and that not all the 
studies are evaluating the same intensities of symptoms. However, the results were similar, even though the authors of these other studies used different questionnaires (according to the respective health services).

Age at menarche in this study (12.4 years) was similar to that found in another Brazilian study, in Barrinha, São Paulo State (12 years and 6 months) 11 and one in Malaysia (12.3 years) 22, but slightly lower than in a study in San Francisco, USA (12.9 years) 23 . There is widespread concept concerning a downward secular trend in age at menarche, explained by various factors, the most important of which is the increase in the obesity rate, which has been occurring mainly in Western countries. According to this concept, there is a biological plausibility in the relationship between age at menarche and the manifestation of premenstrual symptoms and PMS. However, no study investigating this association was found in a literature review on the theme. The results of the current study are in agreement when they show a higher prevalence rate among women with a history of menarche from 7 to 10 years of age for the two intensities of the four symptoms and thus for the score based on them, although this difference was not statistically significant. Although the number of persons studied was not small, subsequent calculation of the sample size showed that it lacked sufficient power to detect differences. The proportion of women who menstruated at the age extremes is less than $10 \%$ in each group, and the prevalence rates, although indicating differences when compared to menarche within the expected age bracket, did not reach statistical significance.

A possible limitation of these findings could be related to the subjectivity of the questions, considering that each symptom was only asked about once during the 22-23-year follow-up.
Figure 1

Distribution, according to reported age at menarche, of women born in Pelotas, Rio Grande do Sul State, Brazil, in 1982 and interviewed in 2004-2005.

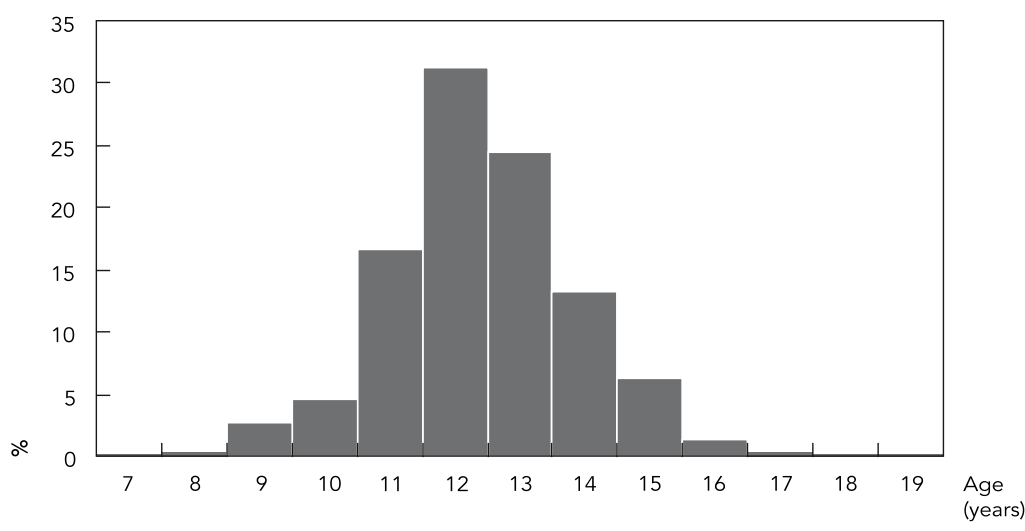

There may also be subjectivity in the reference to the intensity of symptoms. Even so, this possible subjectivity in the instrument was present for all the women that were interviewed and can thus be considered a non-differential source of error.

As mentioned previously, the association between age at menarche and PMS is biologically plausible, considering that girls exposed earlier to higher hormone levels menstruate earlier 2. With early menstruation, they experience premenstrual symptoms for a greater number of menstrual cycles than those who menstruated later. It is also known that girls who menstruate younger take on responsibilities at a younger age, both during pregnancy (inside and outside

Table 3

Prevalence of two different intensities of premenstrual symptoms and the association with different age brackets at menarche among women from the 1982 birth cohort in Pelotas, Rio Grande do Sul State, Brazil.

\begin{tabular}{|c|c|c|c|c|c|c|c|c|c|c|c|}
\hline \multirow{2}{*}{$\begin{array}{l}\text { Age at menarche } \\
\text { (years) }\end{array}$} & \multirow{2}{*}{$\begin{array}{l}\text { Overall distribution } \\
\text { n (\%) }\end{array}$} & \multicolumn{2}{|c|}{ PMS } & \multicolumn{2}{|c|}{ Irritate } & \multicolumn{2}{|c|}{ Anxious } & \multicolumn{2}{|c|}{ Weepy } & \multicolumn{2}{|c|}{ Depressed } \\
\hline & & Moderate & Severe & Moderate & Severe & Moderate & Severe & Moderate & Severe & Moderate & Severe \\
\hline $7-10$ & $131(7.5)$ & 17.6 & 8.4 & 58.0 & 38.9 & 46.6 & 29.0 & 38.9 & 19.9 & 33.6 & 18.3 \\
\hline $11-14$ & $1,470(84.4)$ & 12.7 & 5.4 & 51.8 & 31.9 & 39.1 & 21.2 & 31.0 & 18.2 & 23.4 & 12.4 \\
\hline $15-19$ & $140(8.0)$ & 16.4 & 6.4 & 52.4 & 35.7 & 45.7 & 27.9 & 37.1 & 21.4 & 27.9 & 16.4 \\
\hline$p$ value * & & 0.16 & 0.36 & 0.39 & 0.19 & 0.10 & 0.03 * & 0.08 & 0.61 & 0.02 * & 0.08 \\
\hline
\end{tabular}

PMS: premenstrual syndrome.

* $p$ value $<0.05$ (chi-squared test). 
Table 4

Gross and adjusted prevalence ratios between premenstrual symptoms and moderate and severe premenstrual syndrome (PMS), associated with age at menarche in women born in 1982 in Pelotas, Rio Grande do Sul State, Brazil.

\begin{tabular}{|c|c|c|c|c|c|c|c|c|c|c|}
\hline \multirow{3}{*}{$\begin{array}{l}\text { Age at } \\
\text { menarche } \\
\text { (years) }\end{array}$} & \multicolumn{10}{|c|}{ Crude analysis } \\
\hline & \multicolumn{4}{|c|}{ Moderate symptoms } & \multicolumn{4}{|c|}{ Severe symptoms } & \multicolumn{2}{|c|}{ PMS } \\
\hline & Irritated & Anxious & Weepy & Depressed & Irritated & Anxious & Weepy & Depressed & Moderate & Severe \\
\hline $7-10$ & $1.1(0.9-1.4)$ & $1.2(0.9-1.6)$ & $1.3(0.9-1.7)$ & $1.4(1.1-2.0)$ & $1.2(0.9-1.5)$ & $1.4(1.0-1.8)$ & $1.1(0.7-1.6)$ & $1.5(1.0-2.3)$ & $1.4(0.9-2.1)$ & $1.5(0.8-2.9)$ \\
\hline $11-14$ & 1.0 & 1.0 & 1.0 & 1.0 & 1.0 & 1.0 & 1.0 & 1.0 & 1.0 & 1.0 \\
\hline $15-19$ & $1.0(0.8-1.3)$ & $1.2(0.9-1.5)$ & $1.2(0.9-1.6)$ & $1.2(0.9-1.7)$ & $1.12(0.8-1.5)$ & $1.3(0.9-1.8)$ & $1.2(0.8-1.7)$ & $1.3(0.9-2.1)$ & $1.3(0.8-2.0)$ & $1.18(0.6-2.4)$ \\
\hline Age at & \multicolumn{10}{|c|}{ Adjusted analysis } \\
\hline menarche & \multicolumn{4}{|c|}{ Moderate symptoms } & \multicolumn{4}{|c|}{ Severe symptoms } & \multicolumn{2}{|c|}{ PMS *,§ } \\
\hline (years) & Irritated * & Anxious ** & 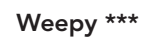 & Depressed * & Irritated $\star \star$ & Anxious \# & Weepy \#\# & Depressed \#\#\# & Moderate & Severe \\
\hline $7-10$ & $1.1(1.0-1.3)$ & $1.2(0.9-1.4)$ & $1.3(0.9-1.7)$ & $1.4(1.1-1.8)$ & $1.2(0.9-1.6)$ & $1.3(1.0-1.7)$ & $1.1(0.8-1.5)$ & $1.5(1.0-2.1)$ & $1.4(0.9-2.0)$ & $1.5(0.8-2.6)$ \\
\hline $11-14$ & 1.0 & 1.0 & 1.0 & 1.0 & 1.0 & 1.0 & 1.0 & 1.0 & 1.0 & 1.0 \\
\hline $15-19$ & $1.0(0.8-1.2)$ & $1.1(0.9-1.4)$ & $1.2(0.9-1.6)$ & $1.1(0.9-1.5)$ & $1.1(0.8-1.5)$ & $1.3(1.0-1.7)$ & $1.1(0.8-1.5)$ & $1.2(0.8-1.8)$ & $1.2(0.8-1.8)$ & $1.1(0.5-2.1)$ \\
\hline
\end{tabular}

* Analysis adjusted for Self-Reported Questionnaire (SRQ-20) and smoking;

** Analysis adjusted for body mass index (BMI), SRQ-20, and smoking;

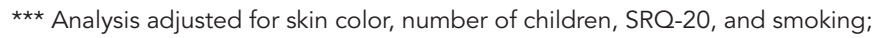

\# Analysis adjusted for BMI, SRQ-20, smoking, and family income;

\#\# Analysis adjusted for number of children, SRQ-20, and smoking;

\#\#\# Analysis adjusted for smoking, years of schooling, and SRQ-20;

$\S$ Analysis adjusted for smoking, SRQ-20, and skin color.

of marriage) and in the work market, assuming adult roles 24 . Thus, physical and/or psychological stress is directly associated with PMS 7, and women that experience stressful situations can present a higher number and intensity of premenstrual symptoms. In the current study, SRQ$20 \geq 8$ was significantly associated with all the premenstrual symptoms, without modifying the association between age at menarche and the PMS outcomes. More research is thus needed on characteristic emotional symptoms of psychiatric disorders accompanying premenstrual symptoms. In the adjusted analysis, various factors were tested that could interfere positively or negatively in the association between age at menarche and both the symptoms and the two forms of measuring PMS, but none of these factors showed any effect modification. It is possi- ble that some other factor, not measured in this study, is causing negative confounding. Thus, other studies should be conducted to further contribute to knowledge in this area.

In conclusion, the higher prevalence rates for all the symptoms and for PMS in girls who menstruated before 10 years of age did not reach statistical significance. The current article describes the characteristics of PMS symptoms in young women from a birth cohort, and the possible association between age at menarche and these symptoms was investigated by controlling for some potential confounding factors. However, in order to study this association, further studies are needed that include other factors still not investigated and that use instruments evaluating the presence of symptoms in at least two consecutive menstrual cycles. 


\section{Resumo}

Os sintomas e a síndrome pré-menstrual foram estudados em mulheres jovens acompanhadas desde seu nascimento. Foram coletadas informações sobre intensidade de quatro sintomas: irritabilidade; ansiedade ou tensão; humor deprimido e labilidade emocional. Síndrome pré-menstrual foi definida de acordo com a intensidade desses sintomas. A associação entre os sintomas e a síndrome pré-menstrual com a idade da menarca foi investigada por meio de regressão de Poisson, ajustando para possiveis fatores de confusão. Em 76\% das mulheres da coorte de Pelotas, Rio Grande do Sul, Brasil, de 1982, que foram acompanhadas até 20042005 os sintomas mais freqüentes foram: irritabilidade e ansiedade. A prevalência de síndrome pré-menstrual foi de 13,4\% e 5,8\% nas intensidades moderada e severa, respectivamente. A idade média da menarca foi de 12,4 $( \pm 1,5)$ anos. A prevalência dos sintomas prémenstruais foi mais alta nas mulheres com menarca antes dos 11 anos, mas estas diferenças não foram estatisticamente significativas. Informações sobre sintomas pré-menstruais e síndrome pré-menstrual são escassas em outros estudos populacionais.

Sindrome Pré-Menstrual; Ciclo Menstrual; Menarca; Mulheres

\section{References}

1. Freeman EW. Premenstrual syndrome and premenstrual dysphoric disorder: definitions and diagnosis. Psychoneuroendocrinology 2003; 28 Suppl 3:25-37.

2. Halbe HW. Tratado de ginecologia. 3a Ed. São Paulo: Editora Roca; 2000.

3. Angst J, Sellaro R, Merikangas KR, Endicott J. The epidemiology of perimenstrual psychological symptoms. Acta Psychiatr Scand 2001; 104:110-6.

4. Wittchen HU, Becker E, Lieb R, Krause P. Prevalence, incidence and stability of premenstrual dysphoric disorder in the community. Psychol Med 2002; 32:119-32.

5 American Psychiatric Association. Diagnostics and statistical manual of mental disorders (DSM IV TR). 4th Ed. Washington DC: American Psychiatric Association; 2000.

6. Silva CML, Gigante DP, Carret MLV, Fassa AG. Estudo populacional de síndrome pré-menstrual. Rev Saúde Pública 2006; 40:47-56.

\section{Contributors}

C. M. L. Silva participated in the fieldwork during the 2004-2005 visit to the 1982 birth cohort, analyzed the data, interpreted the results, and wrote the article. G. C. Minten coordinated the fieldwork during the 2004-2005 visit and participated in the discussion of the results and revision of the article. D. P. Gigante participated in the planning of the most recent visit to the entire 1982 cohort, supervised the fieldwork, oriented the data interpretation, and revised the final version of the manuscript.

\section{Acknowledgments}

The authors wish to thank the Coordenação de Aperfeiçoamento de Pessoal de nível Superior [CAPES, Coordinating Body for Advanced Studies among University Level Personnel], which provided the PhD scholarship for C. M. L. Silva, and the Wellcome Trust through the project Major Awards for Latin America on Health Consequences of Population Change, which funded the 2004-2005 visit to the entire 1982 cohort in Pelotas.
7. Deuster PA, Adera T, South-Paul J. Biological, social, and behavioral factors associated with premenstrual syndrome. Arch Fam Med 1999; 8:122-8.

8. Nicolson P. The menstrual cycle, science and femininity: assumptions underlying menstrual cycle research. Soc Sci Med 1995; 41:779-84.

9. Kac G, Velásquez-Meléndez G, Valente JG. Menarca, gravidez precoce e obesidade em mulheres brasileiras selecionadas em um Centro de Saúde de Belo Horizonte, Minas Gerais, Brasil. Cad Saúde Pública 2003; 19 Suppl 1:S111-8.

10. Biro FM, Khoury P, Morrison JA. Influence of obesity on timing of puberty. Int J Androl 2006; 29:272-7.

11. Tavares CHF, Haeffner LSB, Barbieri MA, Bettiol H, Barbieri MR, Souza L. Idade da menarca em escolares de uma comunidade rural do Sudeste do Brasil. Cad Saúde Pública 2000; 16:709-15. 
12. Ministério da Saúde. Portal da saúde: Sistemas de Informação. Brasília: Ministério da Saúde; 2007. http://portal.saude.gov.br/portal/saude/area. cfm?id_area=1132 (acessado em 27/Fev/2007).

13. Victora CG, Barros FC, Lima RC, Behague DP, Gonçalves H, Horta BL, et al. Estudo de coorte de nascimentos em Pelotas, Rio Grande do Sul, Brasil, 1982-2001. Cad Saúde Pública 2003; 19:1241-56.

14. Victora CG, Barros FC. Cohort profile: the 1982 Pelotas (Brazil) birth cohort study. Int J Epidemiol 2006; 35:237-42.

15. Instituto Brasileiro de Geografia e Estatística. Tábuas completas de mortalidade. Rio de Janeiro: Instituto Brasileiro de Geografia e Estatística; 2005.

16. Instituto Brasileiro de Geografia e Estatística. Censo demográfico, 2000. Rio de Janeiro: Instituto Brasileiro de Geografia e Estatística; 2000.

17. Freeman EW, Kroll R, Rapkin A, Pearlstein T, Brown C, Parsey K, et al. Evaluation of a unique oral contraceptive in the treatment of premenstrual dysphoric disorder. J Women's Health Gend Based Med 2001; 10:561-9.

18. Nogueira CWM, Silva JLP. Prevalência dos sintomas da síndrome pré-menstrual. Rev Bras Ginecol Obstet 2000; 22:347-51.

19. Sveindottir H, Backstrom T. Prevalence of menstrual cycle symptom cyclicity and premenstrual dysphoric disorder in a random sample of women using and not using oral contraceptives. Acta Obstet Gynecol Scand 2000; 79:405-13.
20. Meaden PM, Hartlage SA, Cook-Karr J. Timing and severity of symptoms associated with the menstrual cycle in a community-based sample in the Midwestern United States. Psychiatry Res 2005; 134:27-36.

21. Hsiao MC, Liu CY, Chen KC, Hsieh TT. Characteristics of women seeking treatment for premenstrual syndrome in Taiwan. Acta Psychiatr Scand 2002; 106:150-5.

22. Lee LK, Chen PC, Lee KK, Kaur J. Menstruation among adolescent girls in Malaysia: a crosssectional school survey. Singapore Med J 2006; 47:869-74.

23. Windham GC, Bottomley C, Birner C, Fenster L. Age at menarche in relation to maternal use of tobacco, alcohol, coffee, and tea during pregnancy. Am J Epidemiol 2004; 159:862-71.

24. Gonçalves H, Gigante D. Trabalho, escolaridade e saúde reprodutiva: um estudo etno-epidemiológico com jovens mulheres pertencentes a uma coorte de nascimento. Cad Saúde Pública 2006; 22:1459-69.

Submitted on 06/Mar/2007

Final version resubmitted on 03/Jul/2007 Approved on 13/Jul/2007 